www.jmscr.igmpublication.org

Impact Factor 5.84

Index Copernicus Value: 71.58

ISSN (e)-2347-176x ISSN (p) 2455-0450

crossref DOI: https://dx.doi.org/10.18535/jmscr/v5i10.163

Journal Of Medical Science And Clinical Research

\title{
Normal Pressure Hydrocephalus in a Tertiary Care Centre
}

\author{
Authors \\ Dr Shahul Hameed MM ${ }^{1}$, Dr Rashmi KP ${ }^{2}$, Dr Madhu G Kandathil ${ }^{3}$ \\ ${ }^{1}$ Professor of Medicine, ${ }^{2}$ Assistant Professor of Medicine, ${ }^{3}$ Lecturer \\ Dept of Medicine, Govt T D Medical College, Alappuzha \\ Corresponding Author \\ Dr Rashmi KP \\ Assistant Professor of Medicine, Dept of Medicine, Govt T D Medical College, Alappuzha
}

\begin{abstract}
Normal Pressure Hydrocephalus is a clinical condition associated with gait ataxia, dementia and urinary incontinence and pathologically enlarged ventricles with normal opening pressures. The presenting complaints are highly variable and the characteristic triad is not universally seen. Atypical presentation with subtle Parkinsonian features, Huntingdon movement abnormalities and cognitive dysfunction can resemble many other conditions in the elderly. Impact of cognitive dysfunction in our population with people more than 60 years old still economically vulnerable is significant. NPH is one of the few treatable causes of dementia and thus the need for early recognition and management. Little attention has been given to this potentially treatable condition of the elderly in India. This case series study on 50 patients admitted in Govt TDMC, Alappuzha, with majority older than 70 years of age and of both gender was carried out to determine the spectrum of clinical presentation in patients presenting with clinical or imaging studies suggestive of normal pressure hydrocephalus. In our study, despite all having CT brain suggestive of NPH, the characteristic triad was not universal and many had no clinically correlated findings. Atypical presentation with extra-pyramidal features were seen in $25 \%$ cases with distal resting tremor and impaired distal fine movements being the most common presentation. Gait abnormality was seen in $40 \%$ cases and most had cognitive dysfunction. A strong negative correlation between cognitive behaviour inventory score, UPDRS (Parkinsonism score) and ACE (Cognitive examination score) was found. The study concluded that even though all patients had CT Brain suggestive of NPH, the characteristic triad was not seen in many and extra-pyramidal presentation and cognitive dysfunction could also be considered as an important spectrum of clinical features.
\end{abstract}

\section{Materials and Methods}

This case series study was carried out on 50 patients admitted to the Government T D Medical College, Alappuzha with the diagnosis of Normal Pressure Hydrocephalus during the year 20122013 with the following objectives:
1. Determination of the spectrum of clinical presentation of Normal Pressure Hydrocephalus.

2. Assessment of the incidence and nature of cognitive dysfunction in Normal Pressure Hydrocephalus. 
3. Determination of incidence and type of extra-pyramidal features in patients having Normal Pressure Hydrocephalus.

This study was carried out on patients presenting with symptoms of Normal Pressure Hydrocephalus, of either sex and more than 50 years old admitted to the General Medicine wards and meeting the NPH diagnostic criteria guidelines.

Patients with other co-morbidities known to interfere with cognitive ability and extrapyramidal system functioning, prior history of stroke, lack of imaging studies (CT / MRI) and unwillingness to give consent were excluded from the study.

All the patients meeting the inclusion criteria were made to undergo a detailed neurological examination and subsequently, a structured Proforma with emphasis on Adden- Brookes Cognitive Examination in the local vernacular language, Cognitive Behaviour Inventory (CBI) and UPDRS extra-pyramidal assessment was completed and analysed.

Computer software, Statistical Package for Social Sciences (SPSS) version 10 was used for data analysis. To elucidate the associations and comparisons between different parameters and their proportions, Chi square $\left(\chi^{2}\right)$ test was used as nonparametric test. Logistic regression analysis was performed and for all statistical evaluations, a two-tailed probability of value, $<0.05$ was considered significant.

\section{Observation}

Of the 50 patients studied, 24 were males and 26 were female. The age in our study group varied from a minimum of $65 \mathrm{yrs}$ to a maximum of 88 yrs and mean age of 76 years.

Table 1: Age Distribution

\begin{tabular}{|c|c|c|}
\hline \multirow{4}{*}{50} & Age Details & Years \\
\cline { 2 - 3 } & Mean & 76.16 \\
\cline { 2 - 3 } & Std Deviation & 5.223 \\
\cline { 2 - 3 } & Minimum Age & 65 \\
\cline { 2 - 3 } & Maximum Age & 88 \\
\hline
\end{tabular}

Table \& Chart No2: Sex Distribution

\begin{tabular}{|l|c|c|}
\hline Sex & Frequency & Percentage \\
\hline Male & 24 & 48 \\
\hline Female & 26 & 52 \\
\hline
\end{tabular}

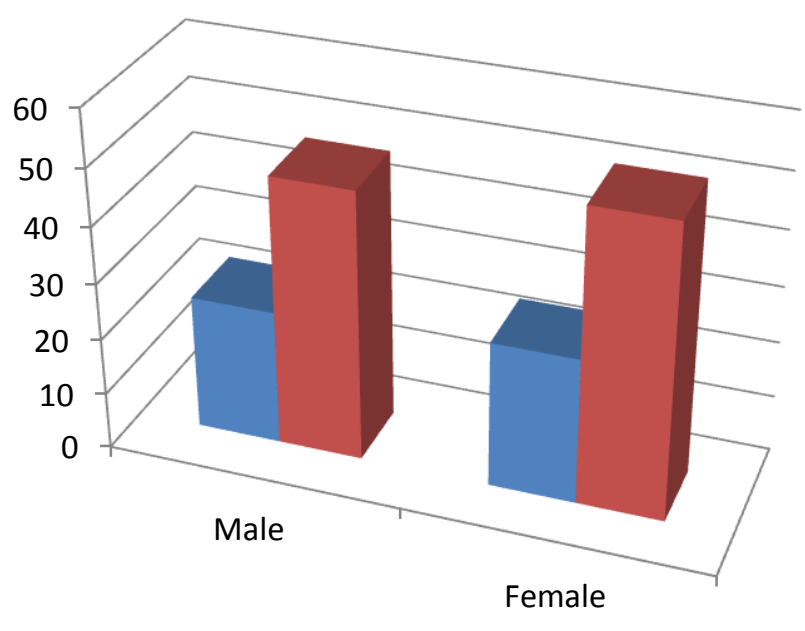

Frequency

Percentage
The minimum and maximum age of presentation in females was 65 and 86 years respectively and in males, this was 66 and 88 years respectively.
Table \& Chart No 3: Distribution of Duration of Illness

\begin{tabular}{|c|c|c|}
\hline Total Patients & $\begin{array}{c}\text { Mean Duration } \\
\text { (months) }\end{array}$ & 23.64 \\
\hline \multirow{3}{*}{50} & Std Deviation & 12.849 \\
\cline { 2 - 3 } & Minimum Duration & 3 \\
\cline { 2 - 3 } & $\begin{array}{c}\text { Maximum } \\
\text { Duration }\end{array}$ & 48 \\
\hline
\end{tabular}




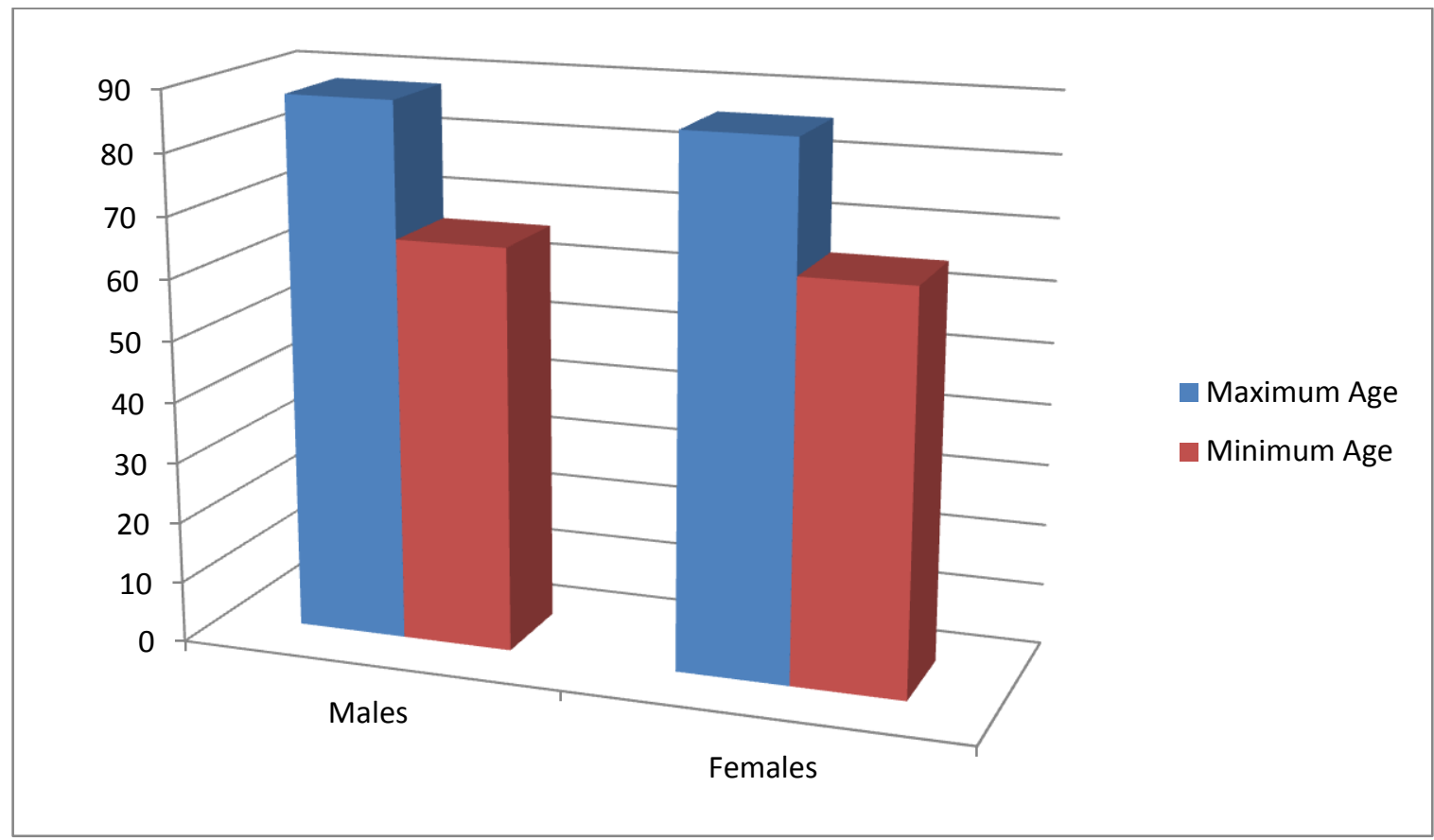

The mean duration of illness was 23 months with variation ranging from a minimum of 3 to a maximum of 48 months. Mean duration of illness was 21 months in female and 26 months in male.

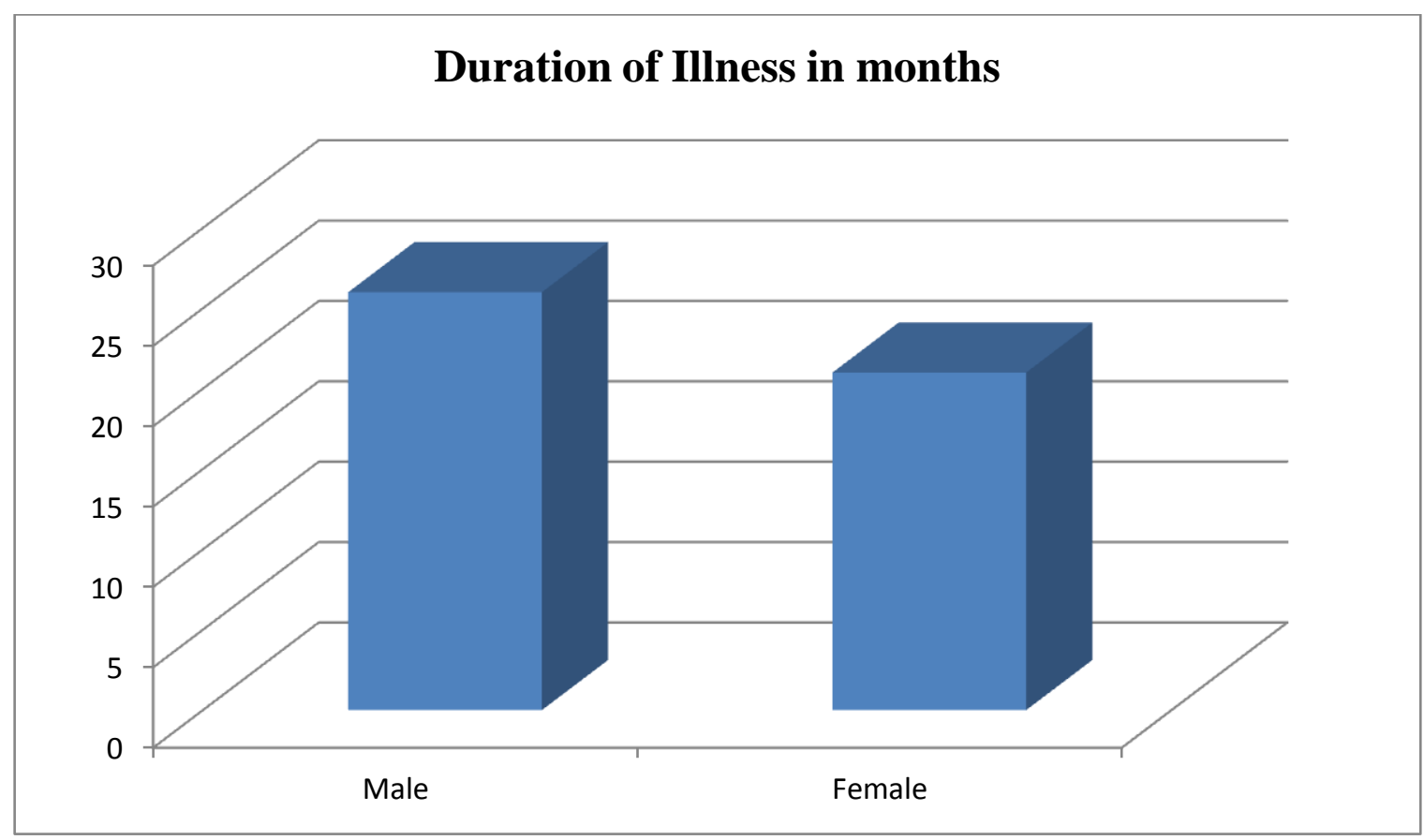

Table \& Chart No 4: Distribution of Duration of Illness (year wise)

\begin{tabular}{|c|c|c|c|c|}
\hline Valid & $\begin{array}{c}\text { Frequency } \\
(\mathrm{n})\end{array}$ & $\begin{array}{c}\text { Percent } \\
(\%)\end{array}$ & $\begin{array}{c}\text { Valid Percent } \\
(\%)\end{array}$ & $\begin{array}{c}\text { Cumulative Percent } \\
(\%)\end{array}$ \\
\hline 1.00 & 16 & 32 & 32 & 32 \\
\hline 2.00 & 11 & 22 & 22 & 54 \\
\hline 3.00 & 17 & 34 & 34 & 88 \\
\hline 4.00 & 6 & 12 & 12 & 100 \\
\hline Total & 50 & 100 & 100 & 0 \\
\hline
\end{tabular}




\section{JMSCR Vol||05||Issue ||10||Page 29426-29437||October}

$32 \%$ patients in our study group had duration of years and $12 \%$ had disease for more than 3 years. illness less than 1 year, $34 \%$ had between 1-2

Table \& Chart No 5: Distribution of Abnormalities in Mentation and Thought Process.

\begin{tabular}{|l|c|c|c|c|}
\hline $\begin{array}{l}\text { Severity of } \\
\text { Abnormalities }\end{array}$ & $\begin{array}{c}\text { Mentation } \\
(\%)\end{array}$ & $\begin{array}{c}\text { Thought } \\
(\%)\end{array}$ & $\begin{array}{c}\text { Depression } \\
(\%)\end{array}$ & $\begin{array}{c}\text { Motivation } \\
(\%)\end{array}$ \\
\hline None & 74 & 80 & 46 & 46 \\
\hline Mild & 6 & 4 & 46 & 38 \\
\hline Moderate & 16 & 4 & 4 & 8 \\
\hline Severe & 4 & 12 & 4 & 8 \\
\hline Very Severe & 0 & 0 & 0 & 0 \\
\hline
\end{tabular}

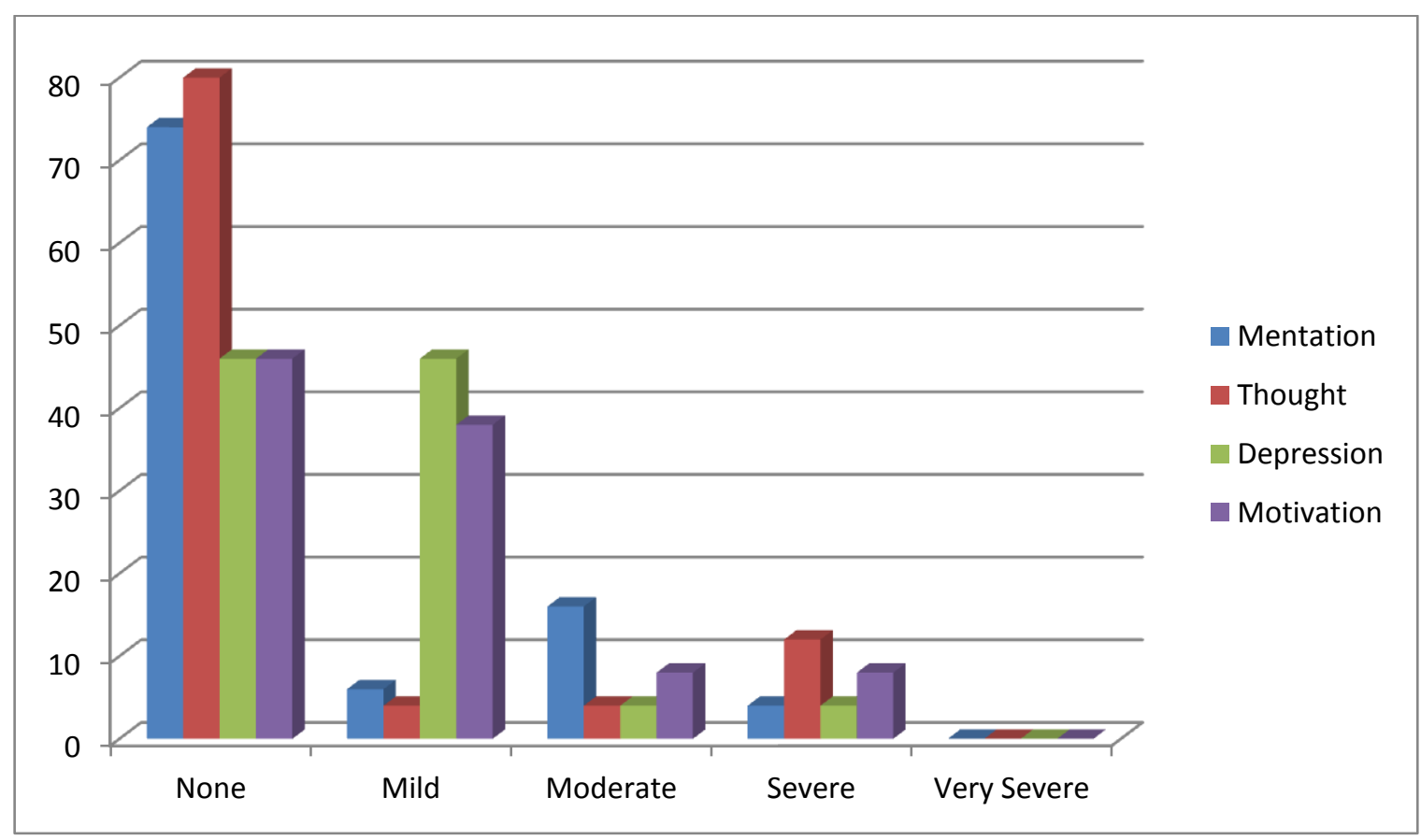

Analysis of UPDRS Score in our study group showed a mean of 11 (SD: 11), median of 10, a minimum of 0 and a maximum of 44 . Intellectual disability was seen in $26 \%$ with $4 \%$ showing severe impairment.

Thought impairment was seen in $20 \%$ of the study group, of which, $12 \%$ had severe impairment.
Depressive mood was seen in 54\% and sustained depression (score 3) was seen in $4 \%$. Lack of motivation was seen in $54 \%$ and $3 \%$ of these displayed losses of initiative in routine jobs.

Table \& Chart No 6: Distribution of Abnormalities in Speech, Salivation and Swallowing.

\begin{tabular}{|l|c|c|c|}
\hline $\begin{array}{l}\text { Severity of } \\
\text { Abnormalities }\end{array}$ & $\begin{array}{c}\text { Speech } \\
(\%)\end{array}$ & $\begin{array}{c}\text { Salivation } \\
(\%)\end{array}$ & $\begin{array}{c}\text { Swallowing } \\
(\%)\end{array}$ \\
\hline None & 48 & 66 & 80 \\
\hline Mild & 40 & 34 & 12 \\
\hline Moderate & 8 & 0 & 8 \\
\hline Severe & 4 & 0 & 0 \\
\hline Very Severe & 0 & 0 & 0 \\
\hline
\end{tabular}




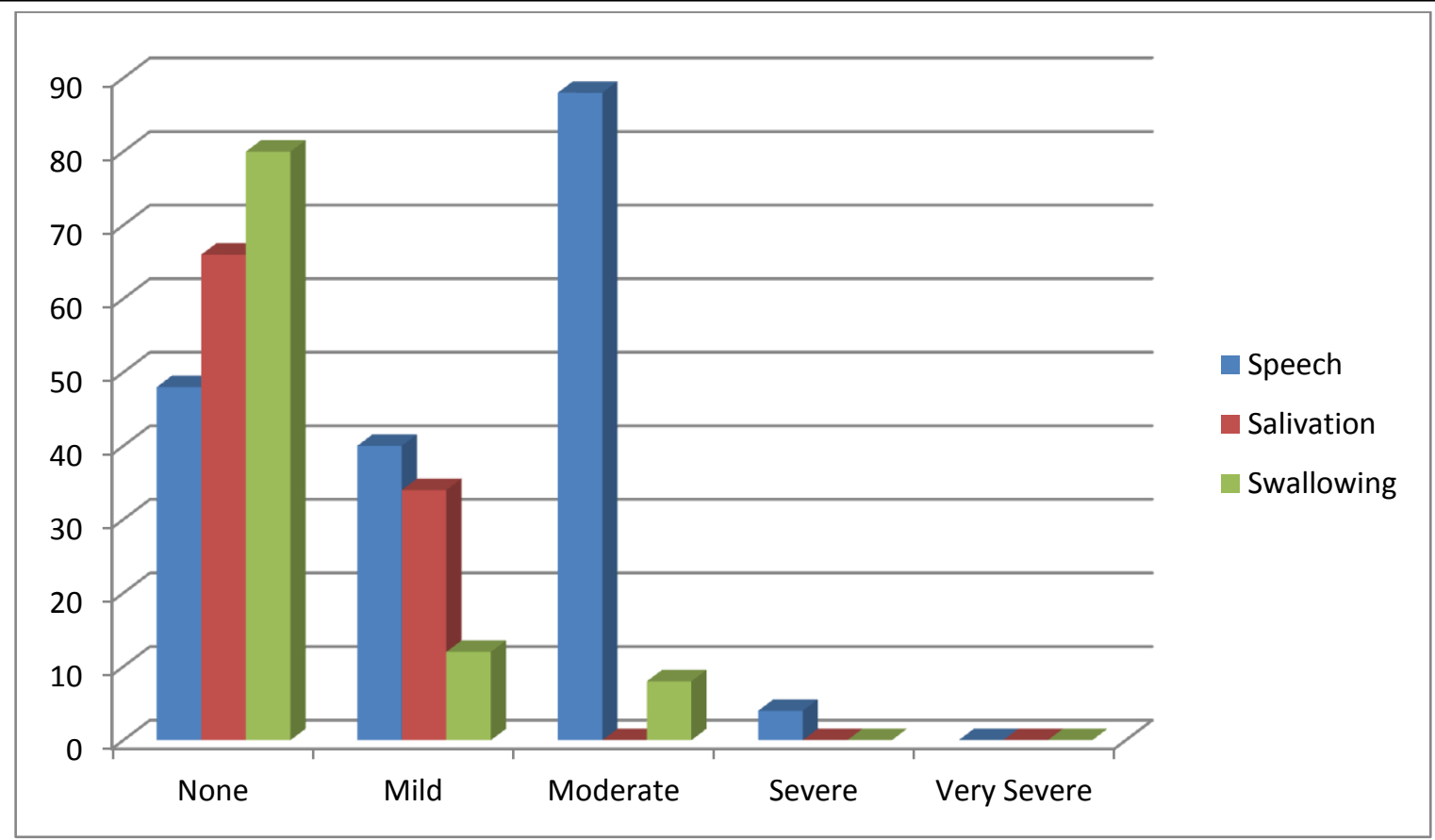

Abnormalities of swallowing were seen in $20 \%$ and occasional choking episodes were seen in $8 \%$.

Table \& Chart No 7: Distribution of Abnormalities in Handwriting, Handling, Dressing and Hygiene.

\begin{tabular}{|l|c|c|c|c|}
\hline $\begin{array}{l}\text { Severity of } \\
\text { Abnormalities }\end{array}$ & $\begin{array}{c}\text { Handwriting } \\
(\%)\end{array}$ & $\begin{array}{c}\text { Handling } \\
(\%)\end{array}$ & $\begin{array}{c}\text { Dressing } \\
(\%)\end{array}$ & $\begin{array}{c}\text { Hygiene } \\
(\%)\end{array}$ \\
\hline None & 64 & 54 & 76 & 68 \\
\hline Mild & 24 & 34 & 12 & 12 \\
\hline Moderate & 4 & 4 & 8 & 8 \\
\hline Severe & 8 & 8 & 4 & 12 \\
\hline Very Severe & 0 & 0 & 0 & 0 \\
\hline
\end{tabular}

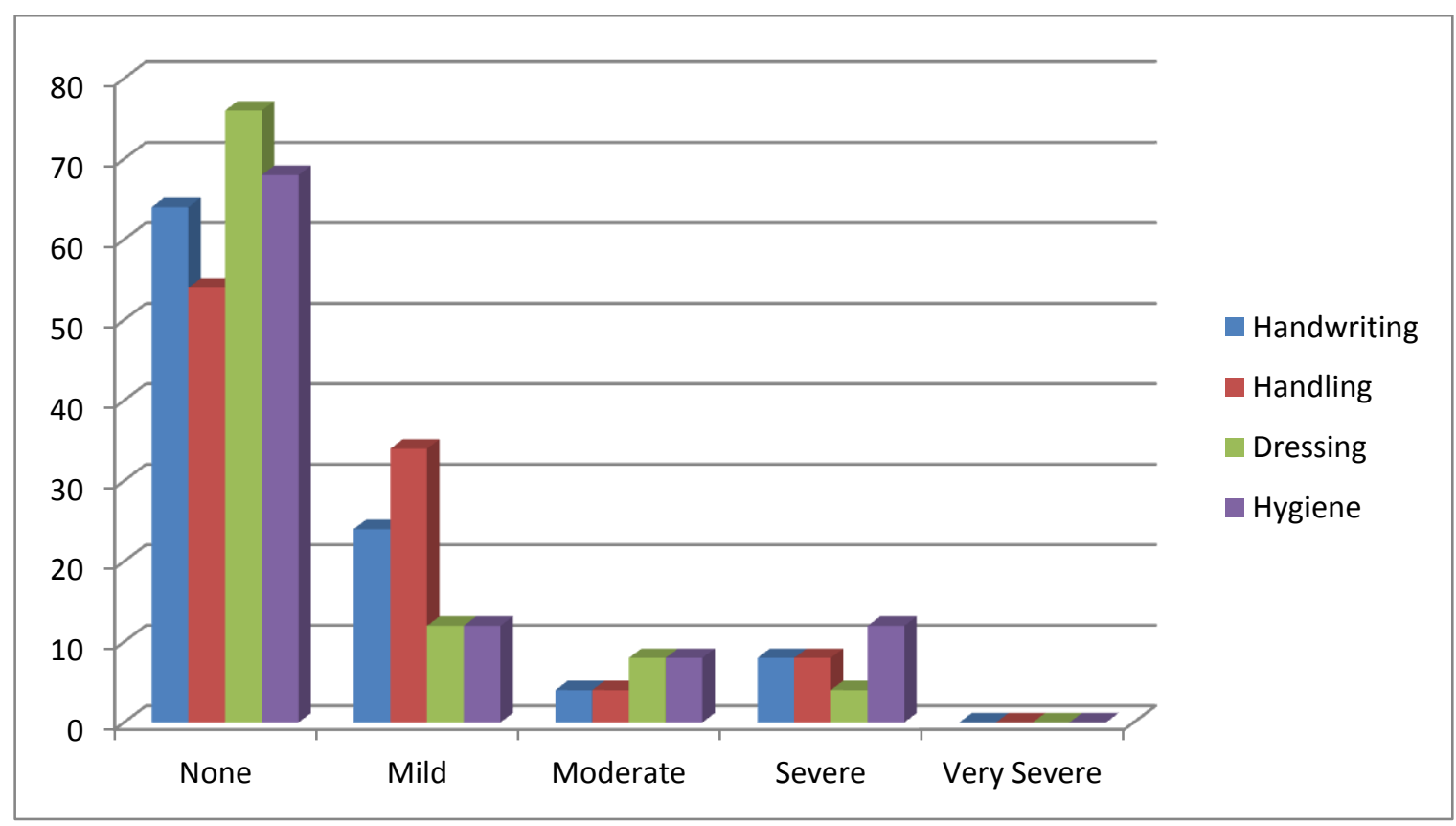

Abnormal handling of things were seen in $24 \%$ and $24 \%$ of these were very severely afflicted.
$36 \%$ had abnormal handwriting. 32\% showed poor hygiene. 
Table \& Chart No 8: Distribution of Abnormalities in Turning in bed, Falling, Freezing and Walking

\begin{tabular}{|l|c|c|c|c|}
\hline $\begin{array}{l}\text { Severity of } \\
\text { Abnormalities }\end{array}$ & $\begin{array}{c}\text { Turning-in-bed } \\
(\%)\end{array}$ & $\begin{array}{c}\text { Falling } \\
(\%)\end{array}$ & $\begin{array}{c}\text { Freezing } \\
(\%)\end{array}$ & $\begin{array}{c}\text { Walking } \\
(\%)\end{array}$ \\
\hline None & 92 & 84 & 72 & 60 \\
\hline Mild & 4 & 12 & 20 & 32 \\
\hline Moderate & 4 & 4 & 4 & 4 \\
\hline Severe & 0 & 0 & 4 & 4 \\
\hline Very Severe & 0 & 0 & 0 & 0 \\
\hline
\end{tabular}

Abnormal turning in bed was seen in 4 patients $(8 \%)$, recurrent falls were seen in $8(16 \%)$, freezing while walking was seen in $14(28 \%)$ and difficulty in walking was seen in 20 patients. $(40 \%)$.

Table \& Chart No 9: Distribution of Tremors, Abnormalities in Facial expression, Resting Tremors and Action Tremor

\begin{tabular}{|l|c|c|c|c|c|}
\hline $\begin{array}{l}\text { Severity of } \\
\text { Abnormalities }\end{array}$ & $\begin{array}{c}\text { Tremors } \\
(\%)\end{array}$ & $\begin{array}{c}\text { Sensation } \\
(\%)\end{array}$ & $\begin{array}{c}\text { Facial } \\
\text { Expression }(\%)\end{array}$ & $\begin{array}{c}\text { Resting Tremor } \\
(\%)\end{array}$ & $\begin{array}{c}\text { Action Tremor } \\
(\%)\end{array}$ \\
\hline None & 44 & 84 & 32 & 40 & 88 \\
\hline Mild & 44 & 16 & 60 & 52 & 8 \\
\hline Moderate & 12 & 0 & 4 & 8 & 4 \\
\hline Severe & 0 & 0 & 4 & 0 & 0 \\
\hline Very Severe & 0 & 0 & 0 & 0 & 0 \\
\hline
\end{tabular}

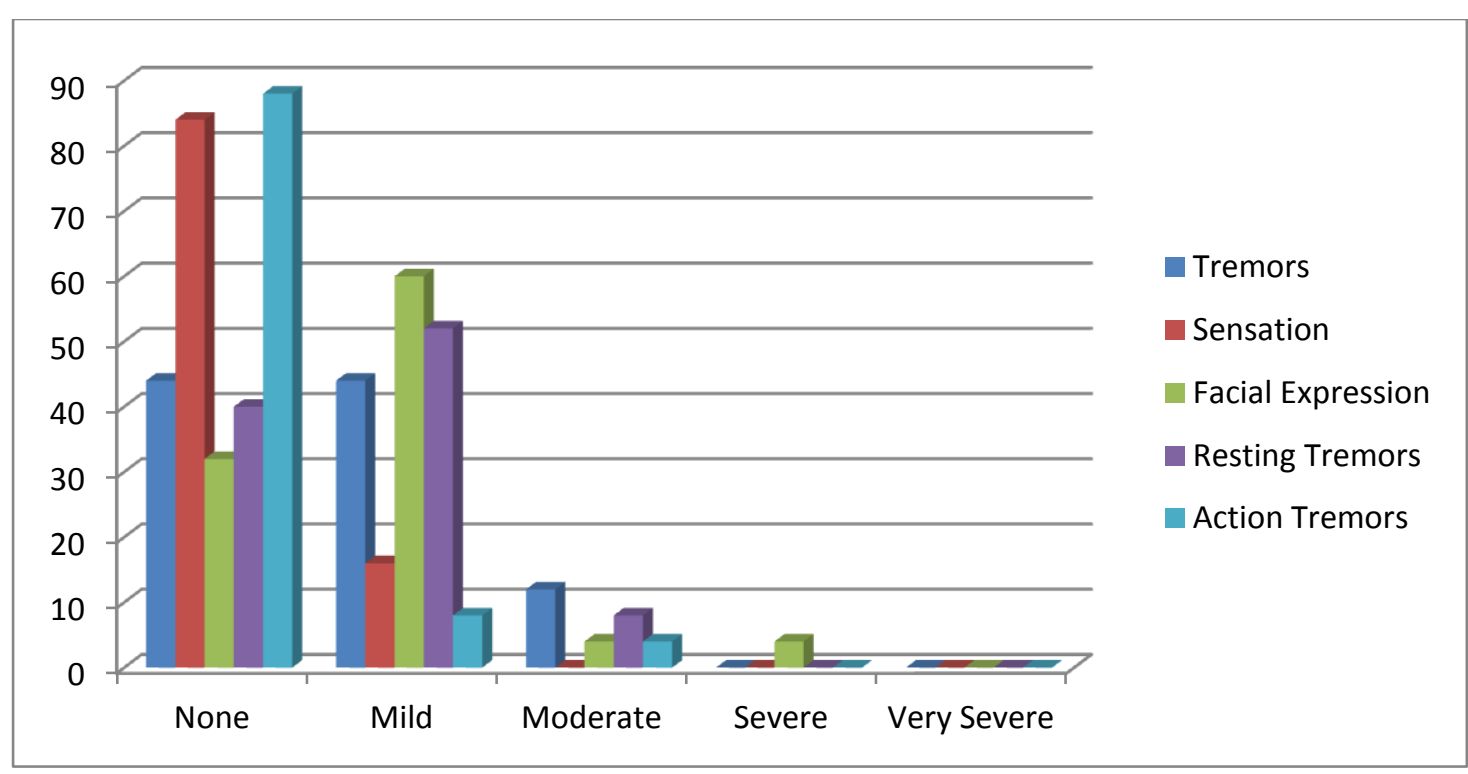

Tremors were seen in $28(56 \%)$ patients, abnormal sensory symptoms were seen in $8(16 \%), 34$ had abnormal facial expressions and 2 had severly impaired facial expressions. Of the 26 patients with tremors, $52 \%$ had slight tremors, $12 \%$ had action tremors.

Table \& Chart No 10: Distribution of Rigidity, Finger Tapping, Hand Movements, Alternate Movements and Leg Agility.

\begin{tabular}{|l|c|c|c|c|c|}
\hline $\begin{array}{l}\text { Severity of } \\
\text { Abnormalities }\end{array}$ & $\begin{array}{c}\text { Rigidity } \\
(\%)\end{array}$ & $\begin{array}{c}\text { Finger Tapping } \\
(\%)\end{array}$ & $\begin{array}{c}\text { Hand } \\
\text { Movement }(\%)\end{array}$ & $\begin{array}{c}\text { Alternate Movement } \\
(\%)\end{array}$ & $\begin{array}{c}\text { Leg Agility } \\
(\%)\end{array}$ \\
\hline None & 60 & 28 & 24 & 24 & 40 \\
\hline Mild & 24 & 48 & 52 & 44 & 36 \\
\hline Moderate & 8 & 16 & 24 & 8 & 8 \\
\hline Severe & 8 & 4 & 0 & 4 & 8 \\
\hline Very Severe & 0 & 4 & 0 & 8 & 8 \\
\hline
\end{tabular}




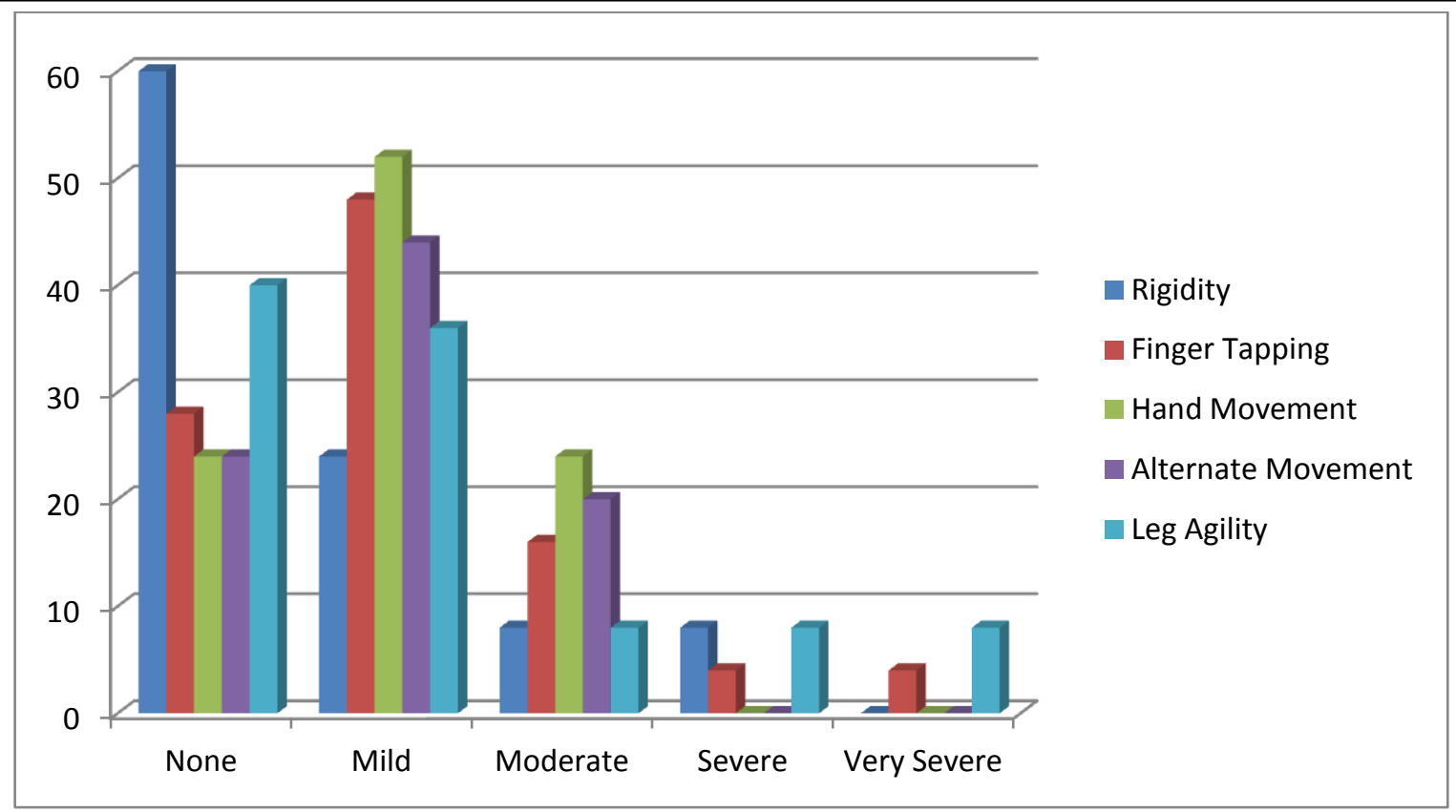

Abnormally rigid muscles were seen in $20(40 \%)$ patients, finger tapping abnormalities in $36(72 \%)$ patients and abnormal hand movements in 36 $(72 \%)$ cases. $38(76 \%)$ patients in the study group had abnormalities in alternate hand movements and reduced leg agility was seen in $30(60 \%)$.

Table \& Chart No 11: Distribution of Abnormalities in arising from chair, Posture, Gait, Posture and Bradykinesia.

\begin{tabular}{|l|c|c|c|c|}
\hline $\begin{array}{l}\text { Severity } \\
\text { Abnormalities }\end{array}$ & $\begin{array}{c}\text { Arising from } \\
\text { chair (\%) }\end{array}$ & Posture (\%) & Gait (\%) & $\begin{array}{c}\text { Bradykinesia } \\
(\%)\end{array}$ \\
\hline None & 52 & 56 & 60 & 52 \\
\hline Mild & 20 & 24 & 20 & 20 \\
\hline Moderate & 20 & 8 & 8 & 20 \\
\hline Severe & 8 & 12 & 4 & 8 \\
\hline Very Severe & 0 & 0 & 8 & 0 \\
\hline
\end{tabular}

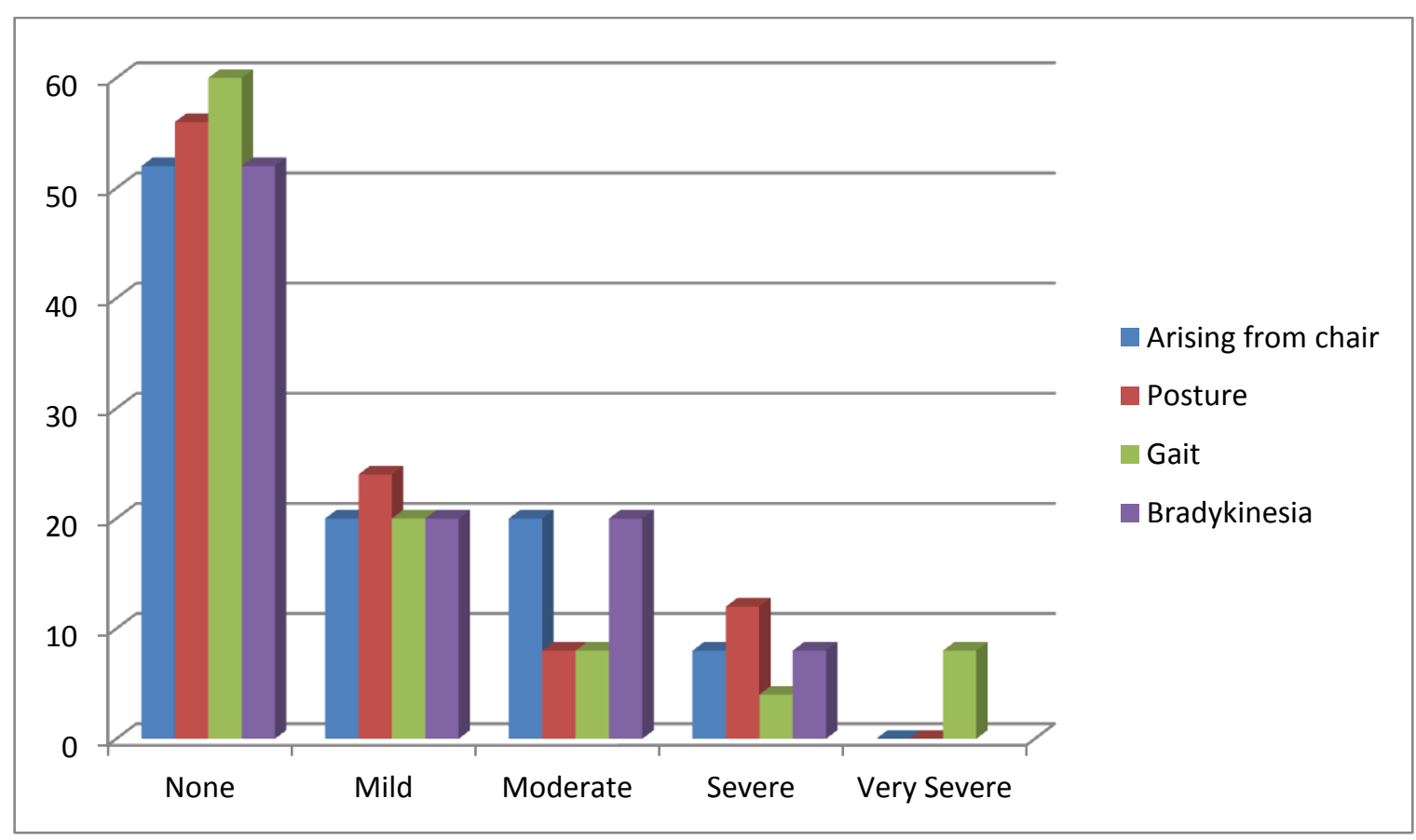


Arising from chair was difficult in 24 (48\%) patients, abnormal posturing in $22(54 \%)$, gait abnormalities in 20 (40\%) and postural abnormality in $18(36 \%)$ patients of our study group. Bradykinesia was seen in 24 (48\%) study subjects.

Table 12: Predictors of UPDRS: Mentation, Mentation and Daily Activities

\begin{tabular}{|l|c|c|}
\hline Domain & Correlation of coefficient & P Value \\
\hline Mentation & 0.858 & 0.000 \\
\hline Daily Activities & 0.952 & 0.000 \\
\hline Motor Impairment & 0.906 & 0.000 \\
\hline
\end{tabular}

Table 13: Linear Regression Analysis for UPDRS with Predictors domains.

\begin{tabular}{|l|c|c|}
\hline Model & $\begin{array}{c}\text { Standard Coefficients } \\
\text { Beta }\end{array}$ & Sig. \\
\cline { 1 - 2 } I (Constant) & 1.374 & .000 \\
\hline Mentation & .580 & .000 \\
\hline Daily Activities & -.712 & .000 \\
\hline Motor & 1.058 & .000 \\
\hline
\end{tabular}

$\mathrm{R}^{2}=0.826$
Statistically significant results $(<0.001 \mathrm{R} 2$ value $)$ on linear regression analysis of UPDRS with mentation, daily activity impairment and motor abnormalities as predictors and an $82.6 \%$ predictive capacity was found in our study.

Analysis of ACE score was done in each domain to determine subtle abnormalities in orientation, attention, verbal fluency, memory, visual ability and language.

Table \& Chart No 13: Sex Wise Distribution of ACE Scores.

\begin{tabular}{|l|c|c|}
\hline & Male $(\mathrm{N}=24)$ & Female $(\mathrm{N}=26)$ \\
\hline Mean & 46.92 & 42 \\
\hline Std Deviation & 22.36 & 23.97 \\
\hline Minimum & 0 & 0 \\
\hline Maximum & 80 & 80 \\
\hline
\end{tabular}

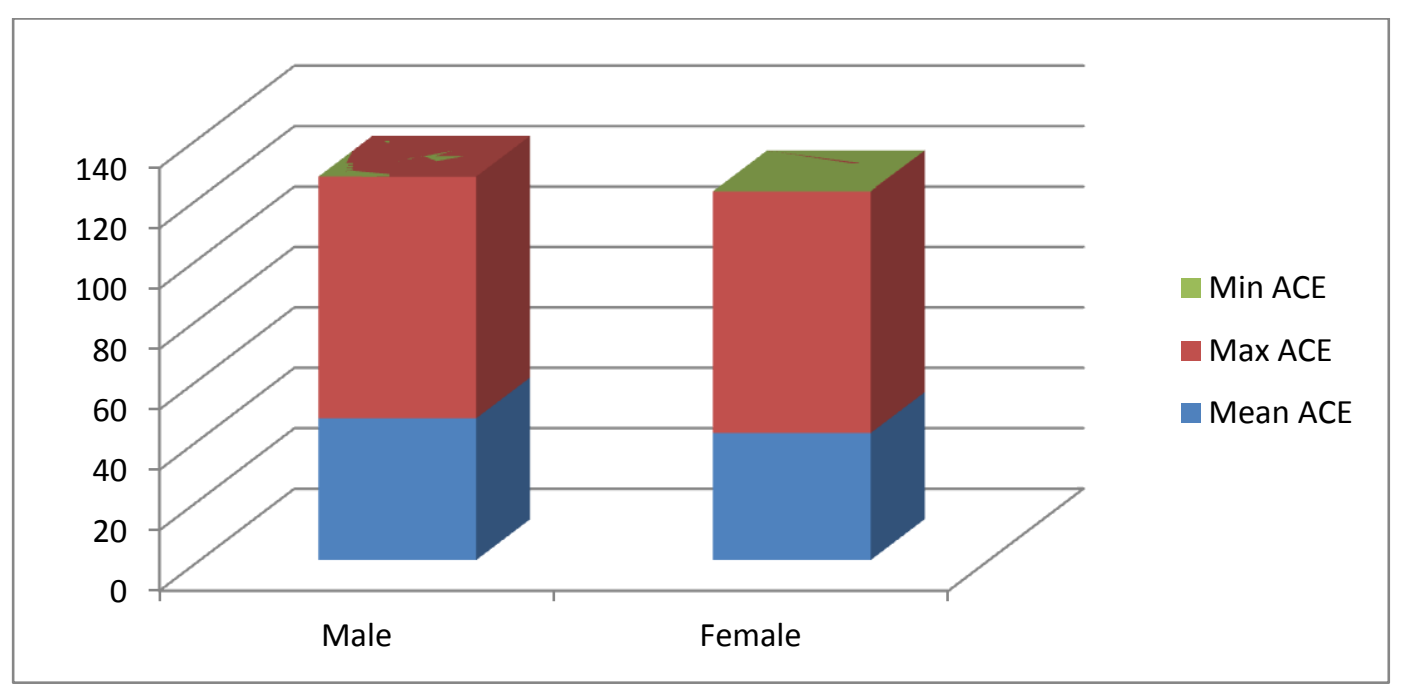

Mean ACE score was 44 in our study group with a maximum of 80 and a minimum of 0 .

Orientation was normal in $40 \%$ and impaired in the rest. $96 \%$ had abnormalities in memory, $96 \%$ had abnormal verbal fluency and $86 \%$ had visual disability.

Table 14: Distribution of ACE Domains

\begin{tabular}{|l|c|c|c|c|}
\hline $\mathrm{N}=50$ & Minimum & Maximum & Mean & Std Deviation \\
\hline Orientation & 0 & 10 & 6.70 & 3.840 \\
\hline Attention & 0 & 9 & 5.18 & 2.422 \\
\hline Memory & 0 & 20 & 6.30 & 4.537 \\
\hline Verbal Fluency & 0 & 15 & 6.58 & 3.320 \\
\hline Language & 0 & 28 & 17.48 & 9.373 \\
\hline Visual Diabilty & 0 & 5 & 2.14 & 1.796 \\
\hline Valid N Test & & & & \\
\hline
\end{tabular}


The minimum score in all domains were 0 . Maximum scores were 10 in orientation, 9 in attention, 20 in memory, 15 in verbal fluency, 28 in language disability, and 5 in visual disability. Mean scores were 6 in orientation with SD of 3.3, 5.18 in attention with SD of 2.4, 6.3 in memory, 6.5 in fluency, 17.4 in language and 2 for visual disability. This model of ACE with domains of orientation, attention, memory, verbal fluency, language and visual disability when analysed with linear regression analysis was found to be statistically significant with $\mathrm{p}<0.001$.

Table 15: Contribution of each Domain to total ACE Score.

\begin{tabular}{|l|c|c|}
\hline Model & $\begin{array}{c}\text { Standardised Coefficient } \\
\text { Beta }\end{array}$ & Sig. \\
\hline (Constant) & -2.38 & 1.000 \\
\hline Visual ability & 0.78 & .000 \\
\hline Language & .406 & .000 \\
\hline Verbal Fluency & .144 & .000 \\
\hline Memory & .196 & .000 \\
\hline Attention & .105 & .000 \\
\hline Orientation & .166 & .000 \\
\hline
\end{tabular}

$\mathrm{R}^{2}=1.000$

Analysis of Cognitive Behaviour Inventory Scale (CBI) was done as a score from a questionnaire obtained from bystanders. Memory impairment, everyday skills, self care, mood, abnormal behaviour, eating habits, sleep, beliefs, stereotypic behaviour and motivation were taken as components. The distribution is depicted in the chart below.
Bivariate analysis of these components displayed strong positive co-relation $(\mathrm{p}<0.001)$ in relation to mood, memory, stereotypic behaviour and motivation. However, self care, everyday skills and sleep abnormalities showed only moderate correlation with the CBI Score. $(p>0.001)$

Table 16: Bivariate Analysis of $\mathrm{CBI}$ and its individual components.

\begin{tabular}{|l|c|c|}
\hline Domain & $\begin{array}{c}\text { Correation Co- } \\
\text { efficient }\end{array}$ & P Value \\
\hline Memory & 0.841 & 0.000 \\
\hline Everyday Skills & 0.750 & 0.000 \\
\hline Self-Care & 0.735 & 0.000 \\
\hline Abnormal Behaviour & 0.842 & 0.000 \\
\hline Mood & 0.803 & 0.000 \\
\hline Beliefs & 0.496 & 0.000 \\
\hline Eating Habits & 0.452 & 0.000 \\
\hline Sleep & 0.600 & 0.000 \\
\hline Stereotypic Behaviour & 0.821 & 0.000 \\
\hline Motivation & 0.893 & 0.000 \\
\hline
\end{tabular}

Pearson correlation coefficient between CBI and UPDRS was $0.246(\mathrm{p}<0.08)$ while that between $\mathrm{CBI}$ and ACE was strongly negative with value 0.746 and $\mathrm{p}<0.001$.

Table 17: Co-relation between ACE, UPDRS and CBI Score.

\begin{tabular}{|l|c|c|}
\hline Domains & Pearson Co-relation & P Value \\
\hline ACE X UPDRS & -0.290 & 0.041 \\
\hline CBI X UPDRS & 0.246 & 0.08 \\
\hline ACE X CBI & -0.746 & $<0.001$ \\
\hline
\end{tabular}

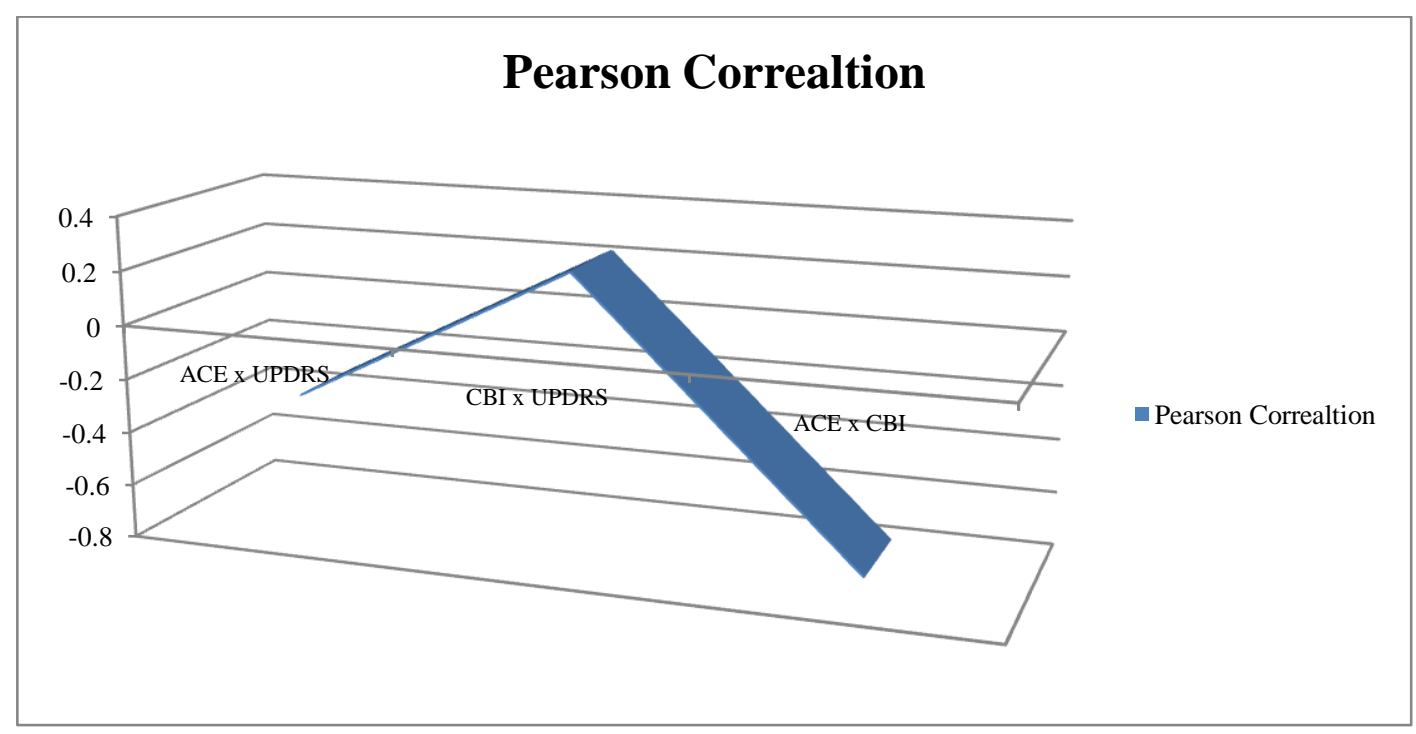




\section{Discussion}

Ever since Hakim and colleagues described a syndrome constellation of progressive cognitive decline, gait difficulties and urinary incontinence in context of ventricular dilatation with normal CSF pressures on lumbar puncture, the emphasis on early detection and management of this potentially curable ause of dementia has gained significance. $^{1-3}$

In the recent years, newer diagnostic techniques, identification of newer prognostic factors and better surgical options have improved patient outcomes ${ }^{4}$. Newer guidelines for diagnosis of the disease were published first in 2005 and have since then been modified and upgraded ${ }^{5}$.

NPH has been classically associated with clinical triad of gait disturbance, dementia and incontinence in patient with communicating hydrocephalus and pathologically enlarged ventricles ${ }^{6}$.

$\mathrm{NPH}$ is remarkable as it is one of the few potentially reversible causes of dementia and the diagnosis is made with clinical findings in background of characteristic neuro-radiology findings. While gait impairment and imbalance typically develop prior to cognitive decline and urinary incontinence in many patients, other atypical presentations have also been now identified $^{7}$.

While most patients with NPH have had symptoms of long standing duration, with lesser options of recovery as the duration increases, temporal course ought to not alone be taken as criteria to exclude treatment options. Further, advanced stages of disease and symptoms show lesser response to interventions. Hence, the need for early and accurate diagnosis of NPH. ${ }^{7-8}$

The multi-factorial causes of the symptoms of dementia, gait impairment and urinary incontinence like Parkinsonson's disease dementia, degenerative dementia, vascular dementia cervical stenosis, peripheral neuropathy bladder instability and prostatomegaly need to be excluded after careful screening. ${ }^{9-10}$ The possibility of multiple causes for the clinical presentation of NPH is very high in the elderly.
Acute hydrocephalus is associated with reduced cerebral perfusion, especially in the frontal lobes, possibly due to stretching of Anterior Cerebral Arteries over corpus. Gait and bladder abnormalities can occur secondary to preferential stretching of the longest nerve fibres as they wind around the enlarged ventricles. Stretching of Cholinergic projections from nucleus basalis to cortical neurons could account for the memory and mentation abnormalities. ${ }^{5-8}$

In our study, Fifty patients with symptoms suggestive of NPH were studied, 24 being male and 26 female. Mean age was 76 years and mean duration of symptoms was 23 months. All the patients had CT brain suggestive of NPH.

Many patients in our study group didn't have all the three components of the characteristic triad described by Hakim $\mathrm{S}$ et al. This was comparable to findings reported by Black PM et $\mathrm{al}^{11}$ and Vanneste JA et $\mathrm{al}^{12}$.

More than $25 \%$ of our patients had atypical presentations with extra-pyramidal features of distal resting tremors and difficulty in fine alternate movements. More than $40 \%$ subjects had gait abnormality. Similar findings were reported in studies by Sudarsky L et $\mathrm{al}^{13}$, Soelberg Sorenson et $\mathrm{al}^{14}$ and Nowak DA et al ${ }^{15}$.

The mean UPDRS score was 11 . The lower the score of UPDRS, the lesser were the extra pyramidal symptoms. Memory was the major cognitive domain affected in majority of the patients. Similar findings were reported by Thomas G et $\mathrm{al}^{16}$ and Van Harten B et $\mathrm{al}^{17}$.

Strong negative co-relations between Cognitive Behaviour Inventory score and ACE score and UPDRS (Parkinsonism Score) and ACE score was found in our study. Even though all patients had Imaging studies suggestive of NPH, many had no correlation with the findings. Similar findings were put forth in earlier studies by Vanneste $\mathbf{J}$ et $\mathrm{al}^{18}$. Hence early identification of this disease is difficult and subject to high index of suspicion.

Our study, being a hospital based was limited the small sample size and by the fact that it might not be a true reflection of the community. Similarly, 
patients were selected based on Radio-imaging findings and not CSF tap test, thus making the diagnosis of NPH as probable rather than possible. Similarly, the questionnaire of neuropsychiatric evaluation was not exhaustive thus leading to probability of missing subtle cognitive abnormalities.

\section{Conclusions}

1) $\mathrm{NPH}$ is disease of elderly usually beyond 0 years with almost equal gender distribution.

2) Average duration of presence of symptoms was 2 years, and all patients had CT findings suggestive of NPH.

3) The characteristic complete clinical triad was not seen in many patients. The corelation between clinical findings and neuro-imaging was erratic.

4) More than $25 \%$ patients had extrapyramidal features with prominent resting tremors, difficult alternative movements and fine distal movements.

5) More than $40 \%$ had gait abnormality.

6) Memory was the most afflicted cognitive domain in our study group.

7) Strong negative co-relation was noticed between Cognitive Behaviour Inventory score and ACE score. Negative co-relation was found between UPDRS (Parkinsonism score) and ACE score.

\section{References}

1. Hakim S, Adams RD. The special clinical problem of symptomatic hydrocephalus with normal cerebrospinal fluid pressure. Observations on cerebrospinal fluid hydrodynamics. J Neuro Sci 1965; 2 (4): 307-27.

2. Hakim S, Venegas JG, Burton D. The physics of the cranial cavity, hydrocephalus and normal pressure hydrocephalus: mechanical interpretation and mathematical model. Surg Neurol 1976; 5 (3): 187-210.
3. Adams RD, Fischer CM, Hakim S et al. Symptomatic occult hydrocephalus with normal cerebrospinal fluid pressure. A treatable syndrome. N Engl J Med 1965; 273: 117-26.

4. Meier U, Konig A, Miethke C. Predictors of outcome in patients with normal pressure hydrocephalus. Eur Neurol. 2004;51(2): 59-67.

5. Relkin N, Marmarou A, Bergsneider M et al. Diagnosing Idiopathic normal pressure hydrocephalus. Neurosurgery $2005 ; 57$ (3 Supplement):S40-52 [discussion ii-v].

6. William MA, Razumovsky AY. Cerebrospinal fluid circulation, cerebral odema and the intracranial pressure. Curr Opin Neurol 1993;6(6): 847-53.

7. McGirt M, Woodworth G, Coon AL et al. Diagnosis treatment and analysis of longterm outcomes in idiopathic normal pressure hydrocephalus. Neurosurgery 2005; 57 (4): 699-705 [discussion 699-705].

8. Kevorkian R. Physiology of incontinence. Clin Geriart Med 2004; 20 (3): 409-25.

9. Marmarou A, Bergsneider M, Klinge $\mathrm{P}$ et al. The value of supplemental prognostic tests for the pre-operative assessment of idiopathic normal pressure hydrocephalus. Neurosurgery 2005; 57 (3 Suppl): S 17-28 [Discussion ii-v].

10. Meier U, Zeilenger FS, Kintzel D. Signs symptoms and course of normal pressure hydrocephalus in comparison with cerebral atrophy. Acta Neurochir (Wein) 1999;141(10):1039-48.

11. Black PM, Oemann RG, Tzouras A. CSF shunts for dementia, incontinence and gait disturbances. Clin Neurosurgery 1985; 32:632-51.

12. Vanneste A. Diagnosis and management of normal pressure hydrocephalus. J Neurol 2000;247(1): 5-14.

13. Sudarsky L, Simon S. Gait disorder in late life hydrocephalus. Arch Neurol 1987; 44(3): 263-7. 
14. Soelberg Sorenson P, ansen EC, Gerris F. Motor disturbances in normal pressure hydrocephalus-special reference to stance and gait. Arch Neurol 19886;43 (1): 34-8.

15. Nowak DA, Topka HR. Broadening a classic clinical triad: the hypokinetic motor disorder of normal pressure hydrocephalus also affects the hand. Exp Neurol 2006; 1988(1): 81-7.

16. Thomas G, McGirt MJ, Woodwoth G et al. Baseline neuropsychological profile and cognitive response to cerebrospinal fluid shunting for idiopathic normal pressure hydrocephalus. Demet Geriart Cogn Disord 2005;20(2-3):163-8.

17. Van Harten B, Courant MN, Scheltens P et al. Validation of the HIV Dementia scale in an elderly cohort of patients with subcortical cognitive impairment caused by subcortical ischemic vascular disease or a normal pressure hydrocephalus. Dement Geriart Cogn Disord 2004;18 (1): 109-14.

18. Vanneste J, Augistiin P, Dirven C et al. Shunting normal pressure hydrocephalus: do the benefits outweigh the risks? A multi-centre study and literature review. Neurology 1992; 42(1): 54-9. 